\title{
Situational Dimensions of a Coordination Theory for Network-based Team Management
}

\author{
Alistair Barros ${ }^{1}$ Mohammad Jabbari ${ }^{1}$ Reihaneh Bidar ${ }^{1}$ Arthur ter Hofstede ${ }^{1}$ Nikolai Kazantsev ${ }^{2}$ \\ ${ }^{1}$ Queensland University of Technology - \{alistair.barros, m.jabbarisabegh, r.bidar, a.terhofstede $\} @$ qut.edu.au \\ 2 The University of Manchester - nikolai.kazantsev@ postgrad.manchester.ac.uk
}

\begin{abstract}
The digital coordination of work in emerging organizational landscapes is at a critical moment of evolution. New challenges are emerging as the modern workplace of enterprises has widened from static partnerships, to open ecosystems and digital communities with highly distributed resources, teams and activities. To address the emerging need for future work coordination models, we provided a modernisation of coordination theory and proposed situational dimensions and facets of work management contexts. As a first exposition of this, we focused on work team management covering formation, resourcing, structuring, and operations. The multidimensional team coordination framework was validated through an open manufacturing case study.
\end{abstract}

\section{Introduction}

The organisational landscape is undergoing unprecedented change through accelerated deregulation, transformation, and digitization. The permanent workforce model, has been gradually offset by the casualisation of labour, with emerging trends towards "just-in-time" workers and crowd-sourcing on an enterprise level. Customer engagement, under the classical provider and consumer relationship, is being re-conceived through the notion of prosumer, through service co-creation in online communities. Process automation, is extending beyond the "backoffice" to the physical environment, through the Internet-of-Things, featuring bi-directional human and robotic co-production. AI algorithms are maturing in self-learning to empower organisations with knowledge and predictive capabilities, raising the stakes for removing the human from the loop.

These and other trends have far reaching consequences, driving fresh impetus for future research on digital work and how workplace related technologies can be coalesced for new waves of organisational transformation. This is underscored by special issues currently underway in JSIS [1] and JAIS [2].

Over the years, workplace technologies have evolved in their support of work coordination at the human and digital interface [3]. This ranges from the merely instrumental via discrete applications (e.g. connecting users and supporting office tasks), to collaborative, through modular integrated applications, and intelligent augmentation, in the advent of "big data". Collaborative technologies have extended the focus of structured coordination to digitally mediated human collaborations through multi-modal interactions. Through enterprise systems, in particular, comprehensive suites of the workplace, e.g. human-resources management, supply chain management, and customer-relationship management, have been widely adopted for cross-organisational work coordination. Their convergence of prior coordination technologies and coverage of domain-specific work concepts and processes, have helped bridged the gap between organisational and automated routines.

Nonetheless, as the modern workplace of enterprises has widened from static partnerships, to open ecosystems and digital communities, new challenges are emerging for workplace technologies and their coordination models. In particular, wider landscapes place greater onus on digital mediation for work coordination $[4,1]$. This, in turn, implies greater support for contextual aspects in workplace technologies, otherwise provided through human and digital coordination complementarities. Yet research studies into organisational contextual awareness of workplace technologies have been limited. They have focused only on examples of instrumental support of coordination capabilities in contemporary organisational settings [5], e.g. the use of social media for collaborative recruitment.

This paper draws its inspiration from the growing recognition that future work coordination models, operating in networked organisations (e.g. global organisations, virtual enterprises, self-organisations in 
online communities), will be predicated on an effective translation of managerial contexts into coordination logic. Specifically, research into these models requires digital/human configurations of digital work coordination - or "assembled arrangements between digital features and human intent and performative actions within organisations." [1]. Our objective is to propose dimensions and facets that can be used in developing a new generation of workflow engine for supporting demand-driven collaborative work in various ecosystems. There are no applications of these dimensions in the practice yet, however we envisioned and encourage further work to be done in this area. To stimulate a research agenda in this strategic direction, the paper provides insights into recurrent areas of work management, amenable for digital work coordination. We position these areas through an extension of coordination theory [6], which has been widely used to theorise about the conceptualisation and development of collaborative support, process-aware and other workplace related systems. Work coordination involves work activity management, work team management, and work resource management. To narrow down the scope of this study, we mainly focused on work management and on work teams. We posit dimensions and their facets for coordination theory, related to specific situations, or management contexts involving the aggregation of interdependent activities for desired outcomes. The situational dimensions are expositional, and not claimed as complete. They are validated through a smart manufacturing case study involving Airbus drawn from a EU Horizon 2020 project ${ }^{1}$.

\section{Extending coordinating theory for digital/human configuration}

Coordination theory provides fundamental concepts for synchronising different activities, managing interdependencies between them, and managing workflow to enable different actors to work together harmoniously [7, 8]. The past decade has seen rapid growth in the number of studies on coordination and how technology can support coordination. However, despite the emergence of workplace technologies which have been developed, composed and adapted through sophisticated digital platforms, coordination problems endure and scale to societal issues. For instance, the third leading cause of fatalities in American hospitals is the coordination failures between workers [9]. Anecdotal studies such as this have shown that the key issue is less in the generic coordinative capabilities of platforms and more in the embedding of coordination

${ }^{1}$ https://cordis.europa.eu/project/id/723336 requirements at the business level into digitalized work. This problem will only be compounded in open work environments involving high distributed resource and activities - e.g. global partner ecosystems, online communities, resources at the "edge" and the like.

The dual considerations of digital and human realms of coordination have had to straddle differences in meaning of activity interdependencies. The emphasis on the digital implies activity management through automated execution [10]. A human perspective, on the other hand, has meant managing attendant aspects surrounding activities, including team formation, actor selection and the appropriation of work spaces and media for communication. The broadened and, at times, ambiguous interpretation of activity interdependencies has led to further and human-centric coordination theories, notably relational coordination. It focused on the nature of actor collaborations and their bidirectional relationships with digital coordination. Our work provides an extension of coordination theory and its underdeveloped notion of situations. Situations, as discussed by Malone and Crowston [6] are specific work management contexts, which resolve the understanding of activities and interdependencies, e.g. a manufacturing division as a manufacturing activity in the context of planning work and a process instance of a product as a manufacturing activity in the context of assembly work. Situations linked to a set of activity interdependencies was intended to resolve such ambiguities, including conflicting goals, and facilitate conceptual transfers between coordination theory and other disciplines.

Our research objective is to provide a first exposition of multi-dimensional situations linked to the management of work teams, without bias as to whether they are at strategic, tactical and operational levels. The different dimensions relate to the fact that teams undergo a wide variety of goals and activities, for example: where should teams be formed, how are they resourced, what do they operate, and how does this change through maturity cycles? Thus, we take a life-cycle view of work team management, identify generalized situational dimensions and provide insights into the nature of activity inter-dependencies. Given the complex and multi-disciplinary phenomena of team management and the range of issues and interpretations, we took a design science approach [11]. First, we developed situational dimensions and facets based on a literature-informed insights drawn from different disciplines. We, then went through a few rounds of iteration to update and refine the dimensions and facets by synthesizing the literature and our current and prior work with networked organizations. As such we were able to develop the situations dimensions and facets from a 
theoretical perspective as well as a practitioner-based perspective. Finally, we demonstrate applicability of situations dimensions and facets based on a case study involving Airbus.

To resolve the complexity and scoping of the dimensions, we have provided different facets of dimensions. In line with the conceptualization of the dimensions, the development of facets follows generalisation principles: generality (reusable concepts); abstraction (from concrete practices and routines); interdependency (of activities and tasks manifesting the goals of the dimension in recurring episodic patterns); traceability (anchoring into different levels, perspectives or adjacencies of aspects, because work aspects function in different levels and guises in organisations); and operational flexibility through different manifestations. Thus, our dimensions and facets are 'constructed' based on salient insights of team management.

\section{Situational dimensions for coordination theory}

To achieve our objectives, we identify situational dimensions for collaborative work situations and explain their facets. ${ }^{2}$ The dimensions and facets we discuss are not exhaustive; however, we mainly focus on the dimensions and facets that can be coordinated.

Dimension 1: work team formation centrality: The need for teams emanates from planning and capacity building, whether in established organisations or organisational structures formed by partnerships. In a productive setting, it reflects the goals of work and expected outputs, requiring the harnessing of human resources and competencies, as social units of coordination [12]. Since work and power is distributed through organisational structures, the key questions that managers face are how to create teams within these and what team restructures are needed for optimal work coordination. Divisional structures have a large bearing on where teams should be situated in terms of an organisation's overarching ownership and governance, though care is needed. However, the planning for teams through the "lens" of organisational hierarchies, as often seen through organisational restructures, can obscure the wider view of work coordination [13]. A process-oriented perspective of organisational structure can overcome such a tendency for team stove-piping, since processes are cross-cutting in contemporary organisations. More detailed insights of work interdependencies are available in processes -

\footnotetext{
${ }^{2}$ In this study we only report a subset of dimensions and facets. A full list of dimensions and facets are available in the technical report upon request.
}

seen through their activity sequences, data exchanges, partner interactions and customer engagement - for team formation considerations [14].

However, work interdependencies are socio-technical and involve more than functional interactions. Increasingly, digital platforms within modern work environments captures digitalized actor collaborations and, thus, the social ties that individuals accrue. These ties, together with the relational connections between individuals, e.g. previous projects, similar professions and skill sets, and shared customers and contracts, are beneficial for analysing the cross-team collaborations. In particular social ties can be used to identify network importance, which indicate influential points of cross-team collaboration [15]. Based on these factors, the following situational dimension emerges for team formation. It involves a broadened notion of centrality, which combines activity interdependencies and actor collaborations, in the planning for where to situate teams in organisations. This consideration applies to different organisational levels, drawn from generalized process-oriented structures, which involve distinct types of work interdependencies and expectations.

Work team formation centrality concerns identifying where teams are needed within inter-dependent organisational units, to meet expected goals and outputs, through the considerations of work coordination effectiveness, based on both activity dependencies and actor ties:

Capability centrality applies to where teams are needed in order to develop organisational capabilities. Capability building is a formative and, often, tactical step of developing competencies and resourcing in readiness for deployment into repetitive or reusable organisational practices. It is typically manifested through: the specialist competencies and reputation of an individual or expert team, who can be entrusted with the responsibility to build a team; competencies drawn from external parties; or emergent solution development, through, for instance, prototype development and pilot trials [16].

Process centrality applies to the need for resourcing business processes which are intended for repeated or reusable operation, involving one or more organisational units. Business processes may be at different levels of operations, seen through process architecture studies [17]. Examples of processes are widely varying, e.g. regular or irregular meetings, management tasks, line-of-business or project tasks, recruiting talent and running events. They are the foundational part of operational practices, and have different types of control and governance, e.g. 
administrative activities, operational guidelines, project plans, and individual production plans.

Service centrality has similarities to process centrality, with exception that the processes driving service delivery, e.g. shared services inside companies and external services delivered to clients for product development, have specialised considerations for externalised expectations and outcomes. Services are demarcated by provider and consumer activities, involving agreed upon value exchange protocols and outcomes [18]. These are reflected through service interactions that apply across the interfaces between providers and consumers. They take on specific and often formal meaning through the rights, obligations and penalties, applied to consumers and providers, and delivery, legal and pricing agreements.

Dimension 2: work team resource planning: The decision to create or restructure teams within specific structures is intentional, and requires sound and feasible resource plans for the next level of management "buy-in". A resource plan includes a functional designation or role type, related competencies and skills, level of position or experience, the required number of roles, the mode and duration of engagement, and the cost of nominated resources for a team. A plan, unaligned with actual work demand, contingencies and the dynamics of environments triggering changing work patterns, will result in repetitive resourcing, increased costs, scheduling difficulties, and, lower management confidence for approvals [19].

For many types of professional roles, resource planning overlays complex interdependencies of work activities, and, thus, inter-dependent structures and resources, including resource sharing across organisational units. This presents significant coordination challenges since the requirements of different stakeholders, including external parties, having direct resource needs or adjacencies, need to be transparently solicited [20]. Trends towards networked and community connected enterprises has also ushered in further considerations for resource planning, including crowd-sourcing and voluntary participation, formal and informal team layers and team virtualisation. Contemporary resourcing strategy extends beyond a purely utilitarian engagement of labour, focused on teams being instrumented through functional roles and competencies. Organisations have instead embraced principles of diversity and equal opportunity, flexible working arrangements, and talent multi-disciplinarity.

Work team resource planning concerns resource-based capacity for the creation or restructure of teams, targeting functional competencies and inter-personal skills, through flexible, multi-disciplinary and effective structures, embodying mutually beneficial employer-employee goals.

Participation applies where resources are planned for formal or informal team roles, over bounded or unbounded duration, on the basis of being assigned through managerial control or by voluntary participation. These modes of participation may occur through different organisational settings, e.g. corporately governed organisations or voluntary, self-organisations in communities. For instance, resource assignment to teams in voluntaristic self-organizations can be directed under their management regime, just as employee participation in specific endeavours of commercial organisation may be volunteered.

Role Composition applies where role-based teams are composed through functional designation or skills and competencies are required for activities [21]. team members each have an "expert role assignment. Role relationships are established in accordance with the functional requirements of the work [21] so that coordination between different individuals is possible.

Team composition applies where teams are formed for extra disciplinary set skills and abilities to support activities [22]. This includes heterogeneous teams within an organisation, in terms of diversity in demographics, personality, formal background, cognitive ability and innovation propensity [23]. team composition is based on task requirements (technical skills) and teamwork requirements (social intelligence) to improve engagement and cohesion within the team.

Incentivisation refers to determining a reward system to provide a positive consequences for team performance or to incentivise individuals [24]. Incentivisation can be planned as formal (e.g., monetary) or informal (e.g., status) and/or through performance evaluation or public recognition. The importance of planning incentives is to control and increase innovation and performance [25].

Dimension 3: work team coordination control: The planning of work teams also needs to take into account the different drivers of coordination, at play, when teams operate within organisations and environments. It needs to answer the question: who or what controls a team when it undertakes work? A common focus of coordination control is on activity interdependencies. This can be seen through coordinative instruments such as project plans, workflow design, and operational work schedules, in which activities are broken down, costed, sequenced, resourced and scheduled. Work planning yields a "blueprint" for team coordination effectiveness, since 
the division of responsibilities, data exchange and knowledge sharing, and shared basis for producing outputs and monitoring progress, is available [26].

This provides a meso view of coordination control, namely the inter-workings of teams, their organisational and external collaborations, and management reporting. However, organisational control, over and above activity interdependencies, provides an important bearing for team coordination control, seen through the leadership styles and models adopted and the different types of functional and cross-functional structures [27]. As such, the meso view of coordination control, focused on work team dynamics, should be pivoted on organisational considerations. At the same time, the macro view should not be obscured - one in which teams and individuals are actors under control of higher levels of management and governance than the teams they operate in [28]. In addition to considerations of these different levels of coordination, various mechanisms are adopted to coordinate activity interdependencies and team work, e.g. digital mediation technologies or dedicated management resources. These have an influence on how teams are coordinated, and need to be considered as part of work team planning.

Work team coordination control concerns the incorporation of micro, meso, macro and supportive views of organisational control and work conduct into work team planning.

Autonomous control is intrinsic to the micro view of work coordination related to elementary parts of team work, or tasks. This level of work carries a degree of autonomy, despite the wider regime of activity interdependencies [29]. Autonomous control is more pronounced in global work settings, where geographically distributed teams are assigned to coarse-grained parts of projects for isolated and autonomous coordination [30] and in online communities with self-organizations.

Organisational control concerns the meso view of work coordination, and different forms of management regimes to manage the activity interdependencies and actor collaborations required to yield outcomes linked to team work goals. The most common regime is hierarchical or vertical authority, in which teams are managed through a hierarchical organisational structure, reflecting formal distribution of authority and reporting in the organisation [31]. Another form is horizontal authority where teams nominate leaders using a shared protocol, combining self-organization and team trust with the vesting of team leadership in individuals [29]. Closely related to it is collective authority which reflects self-organization, shared decision making (e.g. at high executive levels), and adaptive work context.
Digitalized control relates to the utilisation of digitally mediated coordination, e.g. workflow management, industrial robotic systems. It assumes that technologies are endowed with capabilities to manage activity interdependencies, allocate tasks, and support actor collaborations. They are able to monitor, report and appraise progress of especially repetitive work. Digitalized technologies support coordination by enabling information capturing, processing, storage, and exchange [32].

Externalised control involves external coordinators the work team reports to, but are not part of the actual work team. Externalised control applies when a work team makes outsources its coordination to a third-party.

Codified control relates to the planning, policy or contractual instruments, used at individual, team or organisational levels [33]. They include waterfall project schedules, rolling wave project, operational schedules, agile development plans, performance plans, project contracts, enterprise bargains and organisational policies. They contain rules, policies and other forms of constraints and interdependencies, applicable at meso and macro views of coordination.

Dimension 4: work team structure planning: The structure of work forms the basis for a division of labour and is one of the most important factors of work team planning. Resources, assigned through roles, carry competencies and skills which are required for different parts of work. A sound and resilient work team plan effectively allocates resources to these parts, specifically to activities, supporting the tactical and operational goals of the work, and their elementary tasks [34]. Since tasks embody distinct functional capabilities (e.g. managing customer records, assembling parts of a product, delivering goods through a crowd-sourcing transportation service), they form the basis for resources with the requisite competencies and skills. As activities get distributed to locations carrying market, production, social and other advantages, so, too, do resources become distributed. Relatedly, a variety of actor collaborations (e.g. structured or unstructured, multi-modal, digitally mediated) occur in support of productivity scenarios (e.g. order-to-cash) which cut across different activities. As organisations open up through networked enterprise and communities, and new forms of team tiering are emerging (e.g. internal vs. external, formal vs. informal), new ways of work engagement need to be supported (e.g. open work solicitation and participatory design) in work team planning.

Work team structure planning concerns to the dedication and distribution of resources, as part of creation or restructuring of teams, on the basis of work 
structure.

Activity interdependence applies where strong governance is required with frequent interactions among team members and the nature of the work supports a division of labour through distinct and inter-dependent activities. work team structure based in inter-work coupling is dedicated with roles, competencies, experiences and physical resources to meet the work objectives [35].

Activity cohesion refers to the binding of resources to undertake tasks of activities, based on the required functional and social skills and competencies. It provides an intra-activity focus on work team structure planning, requiring analysis of all aspects of an activity [36]. This includes task execution, problem solving, contingency handling, interdependencies with other tasks and actor collaborations. It considers a resource needs for effectively undertaking the tasks, training, mentoring, cross- and up-skilling, multi-modal work collaborations through work space, digital tooling, and other needs should be identified and factored into the work team plan.

Assignment refers to the planned mode of resource assignment for work activities and the degree of flexibility of team members for undertaking work [37]. The extent to which individuals specialize with respect to tasks varies across work team and across levels of the hierarchy within organisations. For instance, in some work teams, an individual (i.e., an analyst) can be assigned to two or more tasks simultaneously, while some other individuals may assigned to a single project at a time [38]. It also refers to the mode where candidates are identified based on their suitability to perform the task and they were given the option to bid for a task or otherwise task could be assigned to the candidates based on their suitability scores [39].

Dimension 5: work team operation management: Unlike the previous dimensions which involved planning considerations for work teams, this dimension is focused on the operational context, in which teams undertake work. Operations involve a wide range of activities, including activity planning, design, and executions as reflected through team responsibilities and resource assignments. This requires that teams shape and use of systems and artefacts, collaborate and connect, supervise, monitor, report, escalate, and refactor, in accordance with their execution plans. Critical to team operations is codified coordination instruments by way of operating procedures, workflows, project plans, worker production schedules and the like. Effective use of systems and artefacts (including centralised and decentralised work environments) needs to be adopted and flexibility of collaboration modalities (e.g. unstructured vs. structured, digitalized vs. manual) and protocols need to strike the right balance for efficiency of outcomes and team trust. The conduct of operations is not static but evolves, as team trust and experience grows.

Therefore, a projection of operational behaviours through distinct stages of team evolution is useful gain nuanced understanding of team operations. We draw on Tuckman's model of team development stages and iteration of this model (e.g., [40]) to focus on team operation evolution, based on developmental stages, i.e., Forming, Storming, Norming, Performing and Adjourning. This model supports work team development from early stages which may involve higher latency, lower trust, and even conflicts between team members to the later stages of work team development which involve higher trust in teams, mutual understanding, and work productivity /efficiency. The different stages and their distinct team operational behaviours imply different requirements for work coordination.

Work team operation management refers to the managing of team work across different stages of experience and maturity, such that teams can coordinate effectively in different operational behaviours appropriate for the stages.

Forming is the stage where team members meet and formulate relationships with each other, which involves involves interaction with team members to establish relationships, assign roles and responsibilities, learn and share knowledge, adopt rules and shape coordination processes and artefacts. The main coordination concern at this stage is to make complementary actors to act like a holistic entity, which entails resolving task uncertainties and co-developing trust, and preparing actors to strive for team emergence.

Storming involves shaping of coordination processes and artefacts for delivering work. This stage also involves creation of agile, flexible, non-deterministic and creative environment for exploring alternatives. The coordination concern at this stage is to improve creativity in task development, at the same time reduce latencies, improve commitment to project plan, improve trust despite competition, and identify managerial options to coordinate unproductive activities. Operational behaviours for activities are developmental as teams establish processes and artefacts for use.

Norming concerns on building some degree of unity to select and focus on the best work delivery plan. This stage involves resolving interpersonal differences, developing the sense of cohesion and personal commitment, therefore helping team members 
to take responsibility for the team progress. To this end, coordination enables work team to organise the ideas around the goal. The coordination concern at this stage is to keeping compliance with rules and procedures and identify criteria to apply whilst selecting one alternative. Operational behaviours for activities consolidate, as teams establish processes and artefacts for reuse.

Performing refers to the stage when the team is mature, organized, and well-functioning. At this stage the work team has a clear and stable structure and the actors are committed to team goals. This involves controlling fulfilment of task requirements, deviations from robust procedures, detecting and resolving problems, monitoring, reporting, and managing team productivity and actor mental health. The coordination concern at this stage is to reduce latency during operation and early detection and resolutions of problems. Operational behaviours for activities accelerate, as teams refine and optimise processes and artefacts for performativity.

Adjourning refers to wrapping up and reaching closure. It involves the time when team members ensure that amicable relationships have been developed so that working together in the future would be advantageous. This is the time when the collaboration is towards to its end, projects/tasks are completed and the work team may or may not work as a team in future. Managers aid to celebrate the team's achievements, enable further networking with team members and capacity building for next projects. It involves sharing intellectual property, sharing social capital, recognising actor success and reputation, making bridges to other projects. The main coordination concern at this stage is to keep the team potential for further projects. It enables actors to get more chances to get similar work in the future.

\section{Applicability: Coordination Practices in Distributed Manufacturing Work - Airbus supply chains}

To discuss the applicability of our proposed dimensions and facets we turn to a case study from Airbus. We summarized in Table 1 how our proposed dimensions and facets are supported or not by the case study. Below we explain in more detail how our proposed dimensions and facets are met. In the aerospace manufacturing the work originates after an airline makes a call for tenders about a new aircraft or semi-parts (i.e. seats, cabin). Larger suppliers are able to bid for work and undertake it, however suppliers who are smaller and medium-sized enterprises (SMEs) need to form teams with other partners, collaboratively, to achieve the size, skills and capacities of requested work work team formation. SME suppliers find partners with composite capabilities while larger suppliers provide their own resources for teams - work team resource planning. Partners exist in the same aerospace industry and may exist in other industries (e.g., in automotive or electronics industry). These suppliers join work teams, coordinated by lead supplier (internal role) or network coaches (external role) - work team coordination control. These roles are envisioned to be enhanced/replaced by an algorithmic mediation tool. The decomposition of work is assigned to each supplier (participant) according to their role in a work team work team structural planning.

The process execution is coordinated by the workflow management systems - work team operational management supporting manufacturing management and operational delivery activities. Different stages of team operation can apply for different projects based on two variables. The first is the stage of maturity of product manufacturing, as existing or altogether new types of products may be developed. The second variable is the team partnership maturity, which relates to prior experience and history of specific partnerships. Accordingly, Airbus promotes use of established or emergent coordination processes and artefacts (e.g. process architecture references for manufacturing) through different projects and architectural reuse once established.

The first dimension, work team formation and the first facet capability centrality applies when the nature of the project involves developmental (product innovations). The innovation stems from the emerging skills and competencies of partners turns into a composite capability. The second facet, process centrality implies the history of previous assignments to do the similar work, however this work is a supportive part, layered usually within contracted services service centrality. Thus, work of an established involves a hybridised process-service delivery model.

The second dimension work team resource planning and the facet participation applies where resources are planned for a potential team, based on work requirements described in calls for tenders. This includes supplier selection criteria on size, capabilities, capacities, and environmental certificates. Role composition is considered where different roles are involved such as: (1) Network coach or facilitator as an external role, responsible for expanding the community around the work team and such community development; (2) Auditor who independently monitors work team operation and ensures compliance to the collaboration rules; (3) Broker who takes over the sales 
function and acquires external orders for a work team; (4) Order manager who is responsible for customer orders; (5) Make-or-Buy Manager is an internal role, which is an interface between work team and its own organization. In planning for team Composition, the partners can stem from dispersed locations, where the work could be done the best way. Beside the functional skills, the lateral skills such as creativity, communication and mediation of partners are of extreme importance for team development.

There are three main forms of incentivisation that bring companies and individuals into collaboration: financial benefits in form of renumeration and the learning effects after interaction with more experienced partner. Also, some smaller companies to work directly with an OEM (i.e. to sign a contract) to increase their status and awareness. Their incentive to work will be much related towards a partnership opportunity with a famous brand.

The third dimension work team coordination control and organisational control applies inside work teams that the work is monitored by lead suppliers who are responsible for the work delivered by other partners. The work distribution schema follows goal decomposition tree and is used to control how partners achieve make, assemble, and deliver types of goals (cf. Supply Chain Operation Reference (SCOR) model). Digitalized control applies when future manufacturing envisions digitalized control via collaboration platforms. These internet-based platforms remove coordinative efforts from OEMs and supplier clusters. Externalized Control applies where the work is coordinated manually by network coaches or by the platform-based services enabling automated coordination. The latter allows to increase the number of work teams working at the same time and the ability of suppliers to take over more work. Codified Control is an envisioned control starts with industrial and environmental certification that is obligatory for a work team. The project contact binds participants to a legal framework, that includes Service Level Agreements specify the expected quality of work team output.

The fourth dimension work team structural organization and activity inter-dependence applies when goal decomposition trees implemented in product ontologies allow coherent inter-firm coupling and the related division of labour to meet the work objectives. Diversity in teams can result in more innovative outputs which brings more benefits for the local economy. Assignment applies when team members get assigned work by lead suppliers (internal role), facilitators (external role) or digital collaboration platform (external role). Supplier can accept or reject the invitation to a
Table 1. Situational dimensions and facets for coordination theory

\begin{tabular}{|c|c|}
\hline Dimension/Facet & Aerospace case study evidence \\
\hline \multicolumn{2}{|c|}{ Dimension 1: Work team formation centrality } \\
\hline $\begin{array}{l}\text { Capability } \\
\text { centrality }\end{array}$ & $\begin{array}{l}\text { ability to find suppliers with required } \\
\text { capabilities to test the market fit. }\end{array}$ \\
\hline $\begin{array}{l}\text { Service } \\
\text { Centrality }\end{array}$ & $\begin{array}{l}\text { ability to compose business services of } \\
\text { suppliers to test the market fit. }\end{array}$ \\
\hline $\begin{array}{l}\text { Process } \\
\text { centrality }\end{array}$ & $\begin{array}{l}\text { ability to reproduce the earlier B2B } \\
\text { process to test the market fit. }\end{array}$ \\
\hline \multicolumn{2}{|c|}{ Dimension 2: Work team resource planning } \\
\hline $\begin{array}{l}\text { Participatory } \\
\text { mode }\end{array}$ & $\begin{array}{l}\text { collaboration rules and team } \\
\text { composition criteria }\end{array}$ \\
\hline $\begin{array}{l}\text { Role } \\
\text { composition }\end{array}$ & $\begin{array}{l}\text { lead supplier, partner, network coach, } \\
\text { auditor, broker, order manager, } \\
\text { make-or-buy manager }\end{array}$ \\
\hline $\begin{array}{l}\text { Team } \\
\text { composition }\end{array}$ & $\begin{array}{l}\text { based on capabilities, certificates, } \\
\text { perceived accumulated team risk }\end{array}$ \\
\hline Incentivization & $\begin{array}{lll}\text { remuneration, } & \text { learning } & \text { effects, } \\
\text { branding effects. } & & \end{array}$ \\
\hline \multicolumn{2}{|c|}{ Dimension 3: Work team coordination control } \\
\hline $\begin{array}{l}\text { Autonomous } \\
\text { control }\end{array}$ & not supported \\
\hline $\begin{array}{l}\text { Organizational } \\
\text { control }\end{array}$ & lead supplier coordinates partners \\
\hline $\begin{array}{l}\text { Digitalized } \\
\text { control }\end{array}$ & $\begin{array}{l}\text { digital platform } \\
\text { collaborative process }\end{array}$ \\
\hline $\begin{array}{l}\text { Externalized } \\
\text { control }\end{array}$ & $\begin{array}{l}\text { network coach is responsible for } \\
\text { work coordination auditors ensure } \\
\text { compliance to collaboration rules }\end{array}$ \\
\hline $\begin{array}{l}\text { Codified } \\
\text { control }\end{array}$ & $\begin{array}{l}\text { legal framework to enforce Service } \\
\text { Level Agreements (SLAs) }\end{array}$ \\
\hline \multicolumn{2}{|c|}{ Dimension 4: Work team structural organization } \\
\hline $\begin{array}{l}\text { Activity } \\
\text { interdependence }\end{array}$ & $\begin{array}{l}\text { bottom-up capability composition or } \\
\text { top-down goal decomposition }\end{array}$ \\
\hline $\begin{array}{l}\text { Activity } \\
\text { cohesion }\end{array}$ & based on manufacturing goals \\
\hline Assignment & $\begin{array}{l}\text { suppliers can accept or reject the } \\
\text { invitation to join a work team from: (i) a } \\
\text { lead supplier; (ii) network coach or (iii) } \\
\text { digital platform. }\end{array}$ \\
\hline \multicolumn{2}{|c|}{ Dimension 5: Work team operational management } \\
\hline Forming & $\begin{array}{l}\text { once the tender is selected, suppliers } \\
\text { must confirm participation, otherwise, } \\
\text { they are replaced. }\end{array}$ \\
\hline Storming & $\begin{array}{l}\text { partners discuss alternatives, clash, } \\
\text { compete to negotiate the work structure. }\end{array}$ \\
\hline Norming & $\begin{array}{l}\text { partners focus on what they need to } \\
\text { the best development and commit to } \\
\text { managerial routines. }\end{array}$ \\
\hline Performing & $\begin{array}{l}\text { partners manufacture their parts and } \\
\text { inform customers if there are any } \\
\text { deviations. }\end{array}$ \\
\hline Adjourning & $\begin{array}{l}\text { partners agree collaborative customer } \\
\text { support and discuss potentials for } \\
\text { further work. }\end{array}$ \\
\hline
\end{tabular}

work team, but the potential scenarios suggest critical suppliers to be obliged keeping idle capacities available to fulfil ramp up orders from OEMs.

The fifth dimension work team operational management and forming stage is when the team has been selected to deliver collaborative manufacturing work after the tendering, every assigned supplier must confirm or reject its participation (in the latter case 
it gets replaced by the alternative candidate). Thus, the team described in the collaborative tendering (or their aggregated capabilities) is reproduced in the reality. A "hackathon" is a good example of what is happening during the storming stage, as suppliers propose alternatives, clash, compete to further specify the work structure, - altogether this has an agile, nonstructured and creative character. In norming stage, suppliers focus on what they need to develop (i.e. select the best alternative) and commit to routines, which are derived from the best practices and agreed between the team members in a face-to-face workshop or using virtual blackboards and online conferencing tools. Then suppliers manufacture the products and inform about deviations (if any) via infrastructure of their interconnected shop-floors in the performing stage. In adjourning stage, supplier agree on post-work collaboration (mainly, information sharing) and discuss potentials for further work in the future.

\section{Discussions and Conclusion}

This paper provided a design science based exposition of future digital work, focused on team work, to inform and guide theoretical developments and technological support for digitally mediated work coordination. We aimed to highlight the complexities of work management contexts, and, yet, the theoretical accessibility of these as tentative or prospective design conceptualisations, towards the growing recognition for a strategic research agenda into confluential future digital work and organisational transformation. To this end, we endeavoured an ambitious though formative renovation of coordination theory to include multi-dimensional situations which contextualise its classical conception of activity interdependencies. By focusing on team management contexts, we drew attention to interdependencies of activities meaning what needs managing as opposed to what is automatically orchestrated - for coordination goals. Our dimensions focused on coordination contexts for: where teams are formed to address productivity goals; what goes into the resource planning of teams; how are teams planned to be operated and structured, given the different team, organisational and broader institutional drivers of work requirements and team operations including changing patterns of operational behaviour as teams evolve and mature.

The design proposal for the multi-dimensional situations and their facets are encouraging for future research but also shed light on significant work that lies ahead. On the positive side, the insights drawn from team management and coordination theories have been sufficiently harnessed into the framework of dimensions and facets sought by the paper. The Airbus case study demonstrated that the complexity of an emerging and open organisational landscape for combined manufacturing efficiency and innovation, can be profiled through the proposed work team coordination dimensions and facets. A challenge was profiling the different facets of the dimensions, for design coherence. Here three different considerations emerged, namely granularity (e.g. the three process-structure levels of work team formation); evolutionary (e.g. the stage based facets of work team operation management); and directive (e.g. the different considerations involved in resourcing and structuring teams through work team resource planning, work team coordination coordination control and work team structure planning). The somewhat coarse-grained nature of the last way of structuring facets suggests a future design refinement.

A second area that is clearly open is the consideration of other work management contexts for profiling as multi-dimensional situations. The coordination of work, as activities and tasks, and the coordination of individual resources, have been researched in the context of workplace related technologies, notably workflow management and emerging social platforms. The profiles of these have bearings on team management dimensions, which could lead to further design refinements.

Finally, as a first and ambitious exposition, our study carried limitations. The case study did not provide insights into the social connectivity and capital of users, highlighted through the design of the dimensions. Further validation work will be required here. In addition, the current state capabilities of technology support need to be be more systematically exposed. Our future work will address the development of further areas of work management through coordination theory, notably activities and resources. We plan to study the digital coordination support through the integrated capabilities of different coordination technologies.

\section{References}

[1] J. Baptista et al., "Digital work and organisational transformation: Emergent digital/human work configurations in modern organisations," 2020.

[2] M. Markus and R. F., "Call for papers special issue: envisioning digital transformation: advancing theoretical diversity," J. Assoc. Inform. Sys., vol. 24, 2020.

[3] M. Watson-Manheim and S. Klein, "Conceptualizing hidden human work in a technology intensive work environment," in OCIS Shanghai Conference at Harvard, 2019.

[4] A. Colbert et al., "The digital workforce and the workplace of the future," 2016. 
[5] P. M. Leonardi and E. Vaast, "Social media and their affordances for organizing: A review and agenda for research," Academy of Mgmt. Annals, vol. 11, no. 1, pp. 150-188, 2017.

[6] T. W. Malone and K. Crowston, "The interdisciplinary study of coordination," ACM Computing Surveys (CSUR), vol. 26, no. 1, pp. 87-119, 1994.

[7] T. Malone and K. Crowston, "What is coordination theory and how can it help design cooperative work systems?," in Proceedings of the 1990 ACM conf. on Computer-supported cooperative work, pp. 357-370, ACM, 1990.

[8] T. Malone, "What is coordination theory?." Paper presented at the National Science Foundation Coordination Theory Workshop at MIT, February 1988.

[9] J. L. CClaggett and E. Karahanna, "Understanding the role of technology in coordination: An affordance perspective," in ICIS, AIS, 2018.

[10] W. M. van der Aalst et al., "Robotic process automation," 2018.

[11] A. R. Hevner, S. T. March, J. Park, and S. Ram, "Design science in information systems research," MIS quarterly, pp. 75-105, 2004.

[12] C. V. Brown, "Horizontal mechanisms under differing is organization contexts," MISQ, pp. 421-454, 1999.

[13] J. H. Gittell and L. Weiss, "Coordination networks within and across organizations: A multi-level framework," J. of management studies, vol. 41, no. 1, pp. 127-153, 2004.

[14] M. Kohlbacher and H. A. Reijers, "The effects of process-oriented organizational design on firm performance," Business process management J., 2013.

[15] W. F. Boh et al., "Expertise and collaboration in the geographically dispersed organization," Organization science, vol. 18, no. 4, pp. 595-612, 2007.

[16] S. Bucher et al., "Contestation about collaboration: Discursive boundary work among professions," Org. Studies, vol. 37, no. 4, pp. 497-522, 2016.

[17] J. Stecjuka et al., "Best practices oriented business process operation and design," in the 9th Workshop on Business Process Modeling, Development and Support Business Process Life-Cycle, pp. 171-184, 2008.

[18] S. L. Vargo and R. F. Lusch, "Service-dominant logic 2025," Int. J. of Research in Marketing, vol. 34, no. 1, pp. 46-67, 2017.

[19] J. G. Wacker and R. R. Lummus, "Sales forecasting for strategic resource planning," Int. J. of Operations \& Production Management, 2002.

[20] D. Strang and D.-I. Jung, "Participatory improvement at a global bank: The diffusion of quality teams and the demise of a six sigma initiative," Organization Studies, vol. 30, no. 1, pp. 31-53, 2009.

[21] G. A. Bigley and K. H. Roberts, "The incident command system: High-reliability organizing for complex and volatile task environments," Academy of Management Journal, vol. 44, no. 6, pp. 1281-1299, 2001.

[22] D. Levi, Group dynamics for teams. SAGE, 2015.

[23] D. Van Knippenberg and J. N. Mell, "Past, present, and potential future of team diversity research: From compositional diversity to emergent diversity," Organizational Behavior and Human Decision Processes, vol. 136, pp. 135-145, 2016.
[24] R. Wageman et al., "Team diagnostic survey: Development of an instrument," The J. of Applied Behavioral Science, vol. 41, no. 4, pp. 373-398, 2005.

[25] O. Gottschalg and M. Zollo, "Interest alignment and competitive advantage," Academy of management review, vol. 32, no. 2, pp. 418-437, 2007.

[26] R. Rico et al., "Team implicit coordination processes: A team knowledge-based approach," Academy of management review, vol. 33, no. 1, pp. 163-184, 2008.

[27] A. R. Jassawalla and H. C. Sashittal, "Strategies of effective new product team leaders," California management review, vol. 42, no. 2, pp. 34-51, 2000.

[28] M. A. Valentine and A. C. Edmondson, "Team scaffolds: How meso-level structures support role-based coordination in temporary groups," 2012.

[29] M. Hoegl and P. Parboteeah, "Autonomy and teamwork in innovative projects," Human Resource Management: Published in Cooperation with the School of Business Administration, The University of Michigan and in alliance with the Society of Human Resources Management, vol. 45, no. 1, pp. 67-79, 2006.

[30] C.-Y. Cheng et al., "Finding the right mix: How the composition of self-managing multicultural teams' cultural value orientation influences performance over time," J. of Organizational Behavior, vol. 33, no. 3, pp. 389-411, 2012.

[31] J. S. Bunderson and P. Boumgarden, "Structure and learning in self-managed teams: Why "bureaucratic" teams can be better learners," Organization Science, vol. 21, no. 3, pp. 609-624, 2010.

[32] J. Kotlarsky et al., "Developing a knowledge-based perspective on coordination: The case of global software projects," in Knowledge processes in globally distributed contexts, pp. 74-105, Springer, 2008.

[33] R. Mirani, "Procedural coordination and offshored software tasks: Lessons from two case studies," Info. \& Mgmt., vol. 44, no. 2, pp. 216-230, 2007.

[34] J. T. Lanzetta and T. B. Roby, "Effects of work-group structure and certain task variables on group performance.," The Journal of Abnormal and Social Psychology, vol. 53, no. 3, p. 307, 1956.

[35] P. Bjørn et al., "Does distance still matter? revisiting the $\mathrm{cscw}$ fundamentals on distributed collaboration," ACM Transactions on Computer-Human Interaction (TOCHI), vol. 21, no. 5, pp. 1-26, 2014.

[36] A. Corominas et al., "A model for the assignment of a set of tasks when work performance depends on experience of all tasks involved," Int. J. of Production Economics, vol. 126, no. 2, pp. 335-340, 2010.

[37] H.-P. Shih, "Technology-push and communication-pull forces driving message-based coordination performance," The J. of Strategic IS, vol. 15, no. 2, pp. 105-123, 2006.

[38] M. A. Meyer, "The dynamics of learning with team production: Implications for task assignment," The Quarterly J. of Economics, vol. 109, no. 4, pp. 1157-1184, 1994.

[39] M. Shen et al., "Multi-criteria task assignment in workflow management systems," in HICSS, pp. 9-pp, IEEE, 2003.

[40] S. G. Harris and R. I. Sutton, "Functions of parting ceremonies in dying organizations," Academy of Management journal, vol. 29, no. 1, pp. 5-30, 1986. 